\title{
Verdade e mito dos dicionários de aprendizes do inglês e do alemão
}

Fact and fiction in English and German Learner's Dictionaries

\author{
Laura Campos de Borba* \\ Félix Valentín Bugueño Miranda ${ }^{* *}$
}

\begin{tabular}{|c|c|}
\hline $\begin{array}{l}\text { RESUMO: Segundo a teoria } \\
\text { metalexicográfica, os dicionários } \\
\text { pedagógicos estão atrelados ao processo } \\
\text { de ensino-aprendizagem de uma língua. } \\
\text { Isso significa que não há como dissociar } \\
\text { essa classe de obras lexicográficas dos } \\
\text { programas de ensino. O objetivo do } \\
\text { presente trabalho é avaliar se uma } \\
\text { modalidade específica de dicionários } \\
\text { pedagógicos, os chamados dicionários de } \\
\text { aprendizes de uma língua estrangeira, } \\
\text { estão efetivamente atrelados a algum } \\
\text { programa de ensino. Ademais, será } \\
\text { analisada a maneira como a língua-alvo é } \\
\text { descrita. Avaliar-se-á um dicionário de } \\
\text { aprendizes de língua inglesa (learner's } \\
\text { dictionary) e outro de língua alemã } \\
\text { (Lernerwörterbuch). Foram escolhidos } \\
\text { esses idiomas em função de dois fatores. } \\
\text { Em primeiro lugar, para ambas as } \\
\text { línguas, há documentos que contêm } \\
\text { diretrizes sobre o seu ensino- } \\
\text { aprendizagem (English Profile (2011) e } \\
\text { Profile Deutsch (2005), respectivamente). } \\
\text { Em segundo lugar, porque ambas as } \\
\text { línguas contam com expoentes de } \\
\text { dicionários de aprendizes. Nossos } \\
\text { resultados demonstram não há uma } \\
\text { correlação entre recursos léxicos } \\
\text { específicos e níveis de aprendizagem. } \\
\text { Comoconsequência disso, os documentos }\end{array}$ & $\begin{array}{l}\text { ABSTRACT: to } \\
\text { metalexicographic theory, pedagogical } \\
\text { dictionaries are concerned with language } \\
\text { teaching and learning. It means that it is } \\
\text { impossible to dissociate these } \\
\text { lexicographic tools from syllabi. The aim } \\
\text { of this paper is to assess if a specific kind } \\
\text { of pedagogical dictionaries, the learner's } \\
\text { dictionaries of a foreign language, are in } \\
\text { fact related to some syllabus. } \\
\text { Furthermore, we analyse how learner's } \\
\text { dictionaries describe their target } \\
\text { language. We assess an English learner's } \\
\text { dictionary and a German learner's } \\
\text { dictionary (a Lernerwörterbuch). We } \\
\text { chose these languages by reason of two } \\
\text { factors. Firstly, there are guidelines for } \\
\text { both languages about their teaching and } \\
\text { learning (such as English Profile (2011) } \\
\text { and Profile Deutsch (2005)). Secondly, } \\
\text { English and German traditions have } \\
\text { archetypes of learner's dictionaries. The } \\
\text { results obtained demonstrate that the lack } \\
\text { of specific lexical resources related to each } \\
\text { reference level doesn't permit to take } \\
\text { advantage from the guidelines for } \\
\text { compiling learner's dictionaries. The } \\
\text { dictionaries we analyzed reflect indeed } \\
\text { the language in use, but they are not } \\
\text { related to any guidelines for English and } \\
\text { German language teaching and learning. }\end{array}$ \\
\hline
\end{tabular}

\footnotetext{
Mestra em Estudos da Linguagem (Lexicografia), Doutoranda PPG-LET UFRGS, lauracborba@hotmail.com.

${ }^{* *}$ Doutor em Filologia Românica, Prof. Lexicografia PPG-LET UFRGS, felixv@uol.com.br.
} 
supracitados não são úteis para a compilação de dicionários. Os dicionários de aprendizes analisados, por sua vez, refletem a norma em uso, mas, evidentemente, não estão atrelados aos documentos norteadores de ensinoaprendizagem do inglês e do alemão.

PALAVRAS-CHAVE: Dicionários de aprendizes de inglês. Dicionários de aprendizes de alemão. Programa de ensino. Ensino-aprendizagem de línguas estrangeiras. Norma real.

KEYWORDS: English learner's dictionaries. German learner's dictionaries. Syllabus. Foreign language teaching and learning. Language in use.

\section{Introdução}

A Lexicografia Pedagógica é aquela que se preocupa com dicionários voltados para o ensino-aprendizagem seja da língua materna, seja de uma língua estrangeira. Na metalexicografia alemã, por sua vez, um dicionário pedagógico se insere no âmbito de um Benutzergruppenorientiertes Wörterbuch [dicionário orientado por grupos de usuários] (ENGELBERG; LEMNITZER, 2009, p. 21). O que essas duas denominações têm em comum é o fato de abarcar obras lexicográficas concebidas para propósitos e públicos-alvo determinados. Evidentemente, esta primeira síntese é ainda muito genérica.

Em primeiro lugar, é fundamental definir o que se entende por lexicografia pedagógica. A expressão pedagógica leva imediatamente ao conceito de pedagogia. No Lexikon Pädagogik (LexPäd, 2010, s. v. ${ }^{1}$ Pädagogik), salienta-se que o termo se refere, entre outras dimensões, ao fato de guiar um indivíduo na busca de conhecimento. A associação com o conceito de heurística, ou seja, a capacidade de descobrir algo novo, é imediata (cf. Wörterbuch der philosophischen Begriffe (WtbPhil 2013, s.v. heuristisch)).

\footnotetext{
${ }^{1}$ Usa-se $s[u b] v[o c e]$ para fazer referência a verbetes de dicionários. Na citação em questão, s.v. salienta que a informação comentada na frase pode ser encontrada no dicionário LexPäd (2010), mais precisamente no verbete Pädagogik.
} 
No entanto, todo e qualquer dicionário é um instrumento heurístico per se, de modo que é necessário deslindar ainda mais o conceito de lexicografia pedagógica, já que, sob a perspectiva supracitada, o Concise Oxford Dictionary of the English Language (COD, 2011) é tão pedagógico como o Oxford Advanced Learner's Dictionary (OALD, 2010), ou, para o caso da lexicografia brasileira, o Dicionário Aurélio da Língua Portuguesa (Au, 2010) seria também tão pedagógico como o Dicionário global escolar Silveira Bueno (GloDEsc, 2016) ${ }^{2}$. Essa afirmação, evidentemente, não é completamente verdadeira ${ }^{3}$. Por isso, o conceito de lexicografia pedagógica precisa de uma maior determinação.

Segundo Hartmann e James (2001, s.v. pedagogical lexicography), lexicografia pedagógica é "o complexo de atividades relacionadas à concepção, compilação, uso e avaliação de DICIONÁRIOS PEDAGÓGICOS"4. A remissão a pedagogical dictionary [dicionário pedagógico] oferece a seguinte definição: "uma obra de referência especialmente desenhada para as necessidades didáticas práticas de professores e

2 Considere-se também o caso dos dicionários que, velada ou abertamente, conferem a si mesmos o status de dicionário pedagógico, dicionário escolar, etc. Assim, por exemplo, não há nada na capa do Novíssimo Aulete Dicionário Contemporâneo da Língua Portuguesa (DContLP, 2011) que permita pensar que se trata de um dicionário desenhado ex professo para auxiliar no processo de ensinoaprendizagem da língua materna. No Front Matter (p. VII - IX), no entanto, há afirmações como “[...] o bom aproveitamento da obra, sobretudo no plano do ensino da língua portuguesa em níveis mais avançados de escolaridade $[\ldots]$ ”; “[...] o universo vocabular das entradas está adequado à nomenclatura exigida pelas matérias curriculares [...]", chegando a se declarar abertamente como "dicionário escolar" (p. VIII) e, inclusive, assinalando que "[...] as 75 mil palavras da nossa língua e quase 20 mil locuções [sc. lematizadas no dicionário são] um número significativo para um dicionário de uso na escola" (p. IX). Não há nenhum parâmetro léxico-estatístico e/ou didático-pedagógico que confirme que a densidade macroestrutural proposta seja um "número significativo para um dicionário escolar". Aliás, muitas das características constitutivas de DContLP (2011) não têm nenhuma utilidade para o usuário escolar. Há segmentos informativos de duvidosa aplicabilidade escolar, tais como as etimologias, a pronúncia dos estrangeirismos e uma descrição da regência verbal que emprega uma nomenclatura sui generis (transitivo direto adverbiado, transitivo direto e relativo, etc.).

3 Embora não faça parte diretamente do escopo do presente trabalho, Borba (2017) provou de forma veraz que, sob determinadas circunstâncias, dicionários que não se intitulam de pedagógicos, particularmente no âmbito do ensino de espanhol como língua estrangeira (ELE), podem ser empregados por aprendizes dessa língua.

4 [A complex of activities concerned with the design, compilation, use and evaluation of pedagogical dictionaries] 
aprendizes de uma língua [...] $]^{5 \prime \prime}$ (idem, s.v. pedagogical dictionary). É evidente que só a partir da definição de dicionário pedagógico é possível compreender melhor a natureza da classe de instrumentos lexicográficos que interessa tratar neste trabalho. Uma palavra-chave neste contexto é o adjetivo didático, empregado na definição do termo dicionário pedagógico. LexPäd (2010, s.v. Didaktik) assinala que o conceito de didática se emprega para denotar "questões sobre a fundamentação, seleção e ordenação de conteúdos do ensino-aprendizagem" ${ }^{6}$. Dito em outros termos, não é possível pensar em lexicografia pedagógica se não se atrelam as obras lexicográficas ditas pedagógicas a conteúdos de ensino-aprendizagem e, mais amplamente, àquilo que a linguística aplicada anglo-saxônica denomina syllabus (cf. RICHARDS; SCHMIDT, 2010, s.v. syllabus).

Considerando o exposto acima, poder-se-iam estabelecer os seguintes parâmetros para um dicionário pedagógico:

1. É uma obra de referência desenhada à luz de um programa de trabalho (syllabus).

2. É uma obra de referência que descreve a norma real contemporânea de uma língua.

3. É uma obra de referência que deve levar em conta as necessidades do seu público-alvo.

O objetivo do presente trabalho é avaliar dicionários de aprendizes de inglês e de alemão no que concerne ao seu viés pedagógico, à descrição das línguas envolvidas e ao potencial de auxílio ao consulente pretenso. Nas seções 2 e 3, discorre-se acerca

5 [A reference work specially designed for the practical needs of teachers and learners of a language $[\ldots]]$.

${ }^{6}$ [Fragen der Begründung, Auswahl und Anordnung von Inhalten des Lehrerns und Lernens] 
de cada parâmetro enumerado acima e as sua implicações para fins de análise das obras; a seção 4, por sua vez, está dedicada à análise de um expoente de cada uma dessas tradições.

\section{Programa de trabalho (Syllabus)}

Um programa de trabalho ${ }^{7}$ consiste em

uma descrição dos conteúdos de um curso de instrução e a ordem na qual devem ser ensinados. Programas de trabalho de ensino de línguas podem estar baseados em diferentes critérios como (a) itens gramaticais e vocabulário [...] (b) recursos linguísticos necessários para diferentes tipos de situação [...] (c) os significados e funções comunicativas que o aprendiz precisa para expressar-se na LíNGUA $\mathrm{ALVO}^{1}[\ldots] \quad(\mathrm{d})$ as habilidades que subjazem a diferentes comportamentos linguísticos ou (e) os tipos de texto que os aprendizes precisam dominar $[\ldots]^{8}$ (RICHARDS; SCHMIDT, 2010, s.v. syllabus).

A definição acima deixa evidente que é possível empregar diferentes variáveis para a elaboração de um programa de trabalho, conforme a perspectiva de ensino de línguas que se adote. Atualmente, o ensino-aprendizagem de línguas estrangeiras é diretamente influenciado pelas orientações presentes no Quadro Europeu Comum de Referência para as Línguas (QECRL, 2001). Prova disso é a adoção, por diversos livros didáticos, de uma escala de níveis proposta pelo documento. O objetivo geral do QECRL (2001) foi contribuir com a mobilidade em território europeu por meio de uma escala unificada de níveis de referência (A1-C2). Isso não o converte automaticamente

\footnotetext{
${ }^{7}$ Neste trabalho, usa-se programa de trabalho e programa de ensino como equivalentes em português para syllabus.

8 a description of the contents of a course of instruction and the order in which they are to be taught. Language-teaching syllabuses may be based on different criteria such as (a) grammatical items and vocabulary [...] (b) the language needed for different types of situations [...] (c) the meanings and communicative functions which the learner needs to express in the TARGET LANGUAGE ${ }^{1}[\ldots]$ (d) the skills underlying different language behavior or (e) the text types learners need to master [...].
} 
em um programa de ensino; na verdade, o documento nem almeja sê-lo, pois salienta que

Não se trata DE MODO ALGUM de dizer aos que trabalham nesta área o que devem fazer e como devem fazê-lo. São levantadas questões, mas não são dadas respostas. A função do Quadro Europeu Comum de Referência não é nem formular os objetivos que os utilizadores devem atingir, nem os métodos que devem usar (QECRL, 2001, p. 11-12; grifos no original).

Isso significa que o QECRL (2001) não se propõe a servir de programa de trabalho - muito embora sua escala de níveis e as diretrizes comunicativas atreladas a cada nível devam servir de referência. Para que se possa entender a relação do QECRL (2001) com os programas de ensino de línguas, é necessário discorrer acerca da concepção de ensino que deu origem a essa proposta e os documentos que serviram de base para esse documento.

Na década de 1970, surgiu uma concepção de ensino de línguas que colocou em dúvida o emprego de estruturas gramaticais como eixo norteador do processo de ensino-aprendizagem de uma língua. Trata-se da abordagem nocional-funcional, a qual predicava que o eixo norteador do ensino deveriam ser noções e funções linguísticas. Conforme Richards e Schmidt (2010, s.v. notional syllabus), as noções são conceitos gerais, como "tempo, quantidade, duração, locação" ${ }^{9}$, entre outros, enquanto que as funções são atos de fala, como "pedir, sugerir, prometer, descrever"10, entre outros.

Segundo a perspectiva nocional-funcional, os recursos linguísticos (unidades léxicas e fraseológicas, flexão verbal e nominal, entre outros), denominados expoentes linguísticos por essa abordagem (cf. Richards e Schmidt (2010, s.v. functional syllabus)),

\footnotetext{
${ }^{9}$ [time, quantity, duration, location]

${ }^{10}$ [requesting, suggesting, promising, describing] 
situam-se em segundo plano. Em primeiro plano, estão as funções e noções, por serem consideradas os principais elementos que conformam a comunicação. Aparentemente, e consoante esse tipo de organização, o que uma abordagem nocional-funcional propõe como programa de trabalho ou syllabus são, na verdade, conjuntos de noções e funções para cada nível de aprendizagem. No que concerne ao ensino de línguas, caberia ao professor ou outro responsável pedagógico a tarefa de determinar quais expoentes linguísticos deveriam ser ensinados em cada etapa de aprendizagem para que os alunos desempenhassem determinadas funções e noções. Por essa razão, há uma já esperada variação entre os expoentes linguísticos elencados por um ou outro curso, ou por um ou outro livro didático, por exemplo. Cada responsável pedagógico elenca de forma ad hoc os expoentes que julgar necessários de acordo não somente com as funções e noções, mas também com os seus propósitos e os propósitos de aprendizagem dos alunos (em se tratando de professores especificamente).

A abordagem nocional-funcional teve como primeiro expoente concreto o programa de trabalho The Threshold Level (1975) para o ensino-aprendizagem de línguas, com ênfase no inglês. O documento propunha que se preparassem os estudantes de línguas estrangeiras para a comunicação nas mais diversas situações diárias, pois punha "ênfase no uso da língua em encontros diretos cara-a-cara"11 (THRESHOLD 1990, 1998, p. 1). Na verdade, tal perspectiva deu início à abordagem comunicativa, sobre a qual se fundamentam o QECRL (2001) e outras perspectivas, como a aprendizagem por tarefas (cf. mais detalhes em Richards e Schmidt (2010, s.v. communicative approach)).

A partir dos anos 1990, lançou-se uma nova edição do documento de 1975 Threshold 1990 (1998) - juntamente com outros planos de trabalho similares: Waystage 1990 (1998), um nível abaixo do Threshold 1990 (1998); Vantage (2001), um nível acima do Threshold 1990 (1998); e Breakthrough (s.d.), um nível abaixo do Waystage 1990 (1998).

\footnotetext{
${ }^{11}$ [emphasis on the use of language in direct person-to-person encounters]
} 
Os predecessores do Threshold 1990 (1998) seguiram a mesma estrutura nocionalfuncional deste, a qual era exemplificada com alguns expoentes linguísticos recomendados para a língua inglesa. A Figura 1 a seguir reproduz o início do inventário de funções e expoentes:

Figura 1 - funções no Threshold 1990 (1998).

\begin{tabular}{|c|c|c|c|}
\hline 1 & $\begin{array}{l}\text { Imparting and seeking } \\
\text { factual information }\end{array}$ & 1.2 .2 & $\begin{array}{l}\text { NP + say, think + complement } \\
\text { clause }\end{array}$ \\
\hline 1.1 & Identifying (defining) & & He -says the 'shop is shut. \\
\hline 1.1 .1 & (with suitable gesture) & 1.3 & correcting \\
\hline & $\begin{array}{l}\text { this (one), that (one) } \\
\text { these, those }\end{array}$ & 1.3.1 & $\begin{array}{l}\text { As } 1.1 \text { and } 1.2 \text {, with } \\
\text { contrastive stress }\end{array}$ \\
\hline 1.1.2 & $\begin{array}{l}\text { It is + me, you, him, her, us, } \\
\text { them }\end{array}$ & & $\begin{array}{l}\text { 'This is the bedroom. } \\
\text { The -train 'has ·left. }\end{array}$ \\
\hline 1.1.3 & $\begin{array}{l}\text { the + NP/this, that, these, those } \\
(+N P)+\text { be + NP } \\
\text { 'This is the , bedroom. } \\
\text { The }{ }^{v} \text { animal over ·there | is } \\
\text { my dog. }\end{array}$ & 1.3.2 & $\begin{array}{l}\text { (correcting a positive } \\
\text { statement) } \\
\text { (e.g. Va'letta is in , Italy.) } \\
\text { No (+ tag) } \\
\text { 'No it 'isn't. }\end{array}$ \\
\hline 1.1.4 & I, you, he, she, it, we, they + be & 1.3.3 & $\begin{array}{l}\text { negative sentences } \\
\text { Va.letta 'isn't in 'Italy. }\end{array}$ \\
\hline & $\begin{array}{l}\text { 'He is the, owner of the } \\
\text { restaurant. }\end{array}$ & 1.3 .4 & $\begin{array}{l}\text { (correcting a negative } \\
\text { statement }\end{array}$ \\
\hline 1.2 & $\begin{array}{l}\text { reporting (describing and } \\
\text { narrating) }\end{array}$ & & $\begin{array}{l}\text { (e.g. We 'didn't go to ,London.) } \\
\text { Yes (+ tag) } \\
\text { 'Yes you }{ }^{\vee} \text { did. }\end{array}$ \\
\hline 1.2 .1 & $\begin{array}{l}\text { declarative sentences } \\
\text { The 'train has, left. }\end{array}$ & & \\
\hline
\end{tabular}

Fonte: Threshold 1990 (1998, p. 28).

Na Figura 2, reproduz-se o início do inventário de noções e respectivos expoentes:

Figura 2 - noções no Threshold 1990 (1998).

\begin{tabular}{|llll|}
\hline 1 & Existential & 1.2 & $\begin{array}{l}\text { presence, absence } \\
\text { here, not here, there, not } \\
\text { there, away }\end{array}$ \\
existence, non-existence \\
There is + NP \\
There's no + NP \\
$\begin{array}{l}\text { There isn't any + NP } \\
\text { the verbs to exist, to become, } \\
\text { to make (as in: She 'made a } \\
\text { new, dress.) }\end{array}$ & $1.3 \begin{array}{l}\text { availability, non availability } \\
\text { to have (got) } \\
\text { There is + NP } \\
\text { There's no + NP } \\
\text { There isn't any + NP }\end{array}$ \\
\hline
\end{tabular}

Fonte: Threshold 1990 (1998, p. 48). 
Os quatro documentos supracitados, conhecidos como T-series, serviram de base para a reelaboração de programas de trabalho de cursos de inglês e de materiais didáticos- para citar alguns exemplos. Devido ao sucesso da iniciativa, as orientações gerais acerca das funções e noções foram transpostas a outras línguas europeias e geraram documentos similares para cada uma.

Em meio a esse cenário, o Conselho da Europa compilou uma base comum de referência para o ensino, aprendizagem e avaliação de línguas estrangeiras em território europeu: o QECRL (2001). A partir dos documentos T-series, propôs-se uma escala de níveis de referência de caráter genérico (i. e., sem atrelar-se a uma língua específica, como os T-series para o inglês) e fundamentada a partir da abordagem nocional-funcional: A1 (antigo Breakthrough (s.d.)); A2 (antigo Waystage 1990 (1998)); B1 (antigo do Threshold 1990 (1998)); B2 (antigo Vantage (2001)); C1 e C2 (níveis mais avançados). Da mesma forma que seus predecessores, e conforme já comentado anteriormente, o QECRL (2001) não se propõe a ser um programa de ensino, mas sim uma obra de referência para guiar a elaboração deste tipo de documento a partir de uma abordagem comunicativa (por considerar as funções e as noções como pilares que sustentam o ensino-aprendizagem). É pertinente salientar, entretanto, que tal posicionamento diverge do papel que o QECRL (2001) tem como obra de referência. Parece não fazer sentido denominar-se documento de referência e oferecer descritores de desempenho para cada nível a partir de funções e noções comunicativas, por um lado, e, ao mesmo tempo, alertar que não é necessário seguir as suas próprias orientações, por outro lado.

Identificar os expoentes linguísticos de cada língua que permitem a realização das funções e noções comunicativas do QECRL (2001) está muito longe de ser uma tarefa fácil. Ante a concepção teórica do mesmo, a maneira mais coerente de montar um programa de ensino seria investigar em corpora quais expoentes linguísticos realmente são utilizados em uma língua quando se realizam ditas funções e noções. 
Entretanto, sob o ponto de vista metodológico, atualmente não há como levar a cabo semelhante trabalho.

As críticas ao caráter genérico do QECRL (2001) e as dificuldades em estabelecer uma correspondência com os expoentes de uma língua levaram o Conselho da Europa a estimular a produção de documentos complementares para suprir a demanda por transposições do mesmo a línguas específicas. Tais documentos são as Descrições de Níveis de Referência, que existem para o inglês, alemão, espanhol, francês, entre outras línguas. O objetivo desse tipo de documento é identificar as formas (gramática e vocabulário) de cada língua que permitem a comunicação das funções e noções presentes no QECRL (2001). Apesar de serem originários de uma mesma base e de seguirem determinações do próprio Conselho da Europa para a sua elaboração, as Descrições de Níveis de Referência (doravante, DNR) diferem significativamente entre si no tocante à metodologia empregada para sua compilação e aos tipos de informações fornecidos. Para fins deste trabalho, as próximas duas subseções tratam especificamente dos DNR do inglês e do alemão.

\subsection{DNR do inglês: English Profile}

Para o inglês, o DNR mais desenvolvido é o English Profile (EP, 2011) ${ }^{12}$. Seu objetivo é produzir uma base de dados que apontem quais expoentes linguísticos (gramaticais e de vocabulário) os aprendizes de inglês empregam e que permitem a

\footnotetext{
${ }^{12}$ Há outra iniciativa, fruto de uma parceria entre o Consulado Britânico e a European Association for Quality Language Services: A Core Inventory for General English (CIGE, 2011). A proposta abarca os níveis de $\mathrm{A} 1$ a $\mathrm{C} 1$ e fornece de maneira sucinta um inventário de itens de funções, tópicos gramaticais, marcadores discursivos, temas de vocabulário e tópicos gerais para cada um desses níveis (CIGE, 2011, p. 10). Conforme o documento, seu objetivo é esclarecer aos professores "o que ensinar em cada nível do QECRL" [what to teach at each CEFR level] (CIGE, 2011, p. 9). Da mesma forma que o QECRL (2001) e o EP (2011), salienta-se que "o objetivo não é dizer aos professores o que ensinar ou prescrever uma metodologia de ensino em particular" [the aim is not to tell teachers what to teach or to prescribe a particular teaching methodology] (ibid.). Novamente, nota-se uma contradição entre o papel social atribuído ao documento por seus próprios compiladores e o que os mesmos defendem como não sendo objetivos do mesmo.
} 
sua classificação em cada nível de proficiência do QECRL (2001). Em outras palavras, os compiladores do EP (2011) investigam quais foram os expoentes linguísticos que indivíduos classificados como nível B1 de proficiência, por exemplo, utilizaram - e que possibilitaram a comunicação das funções e noções previstas para esse nível. Ademais, os compiladores do EP (2011) investigam quais funções são normalmente atreladas a cada nível.

O EP (2011) possui três eixos de investigação: English Grammar Profile, English Vocabulary Profile e English Functions Profile.

O English Grammar Profile (EGP) se fundamenta no pressuposto de que "há certas propriedades linguísticas que são características e indicativas de proficiência na L2 em cada nível"13 (EP, 2011, p. 9). Seu objetivo é descrever os expoentes gramaticais mais prototípicos de cada nível de aprendizagem do QECRL (2001), como “perguntas indiretas" ou "sentenças simples usando infinitivo" (EP, 2011, p. 11). As informações do EGP estão disponíveis tanto sob a forma de uma ferramenta gratuita na Internet como também no EP (2011, p. 11-35).

Os dados que conformam o EGP são coletados a partir do Cambridge Learner Corpus, um corpus de produções provenientes de testes de proficiência em inglês. Um fato curioso sobre essa fonte é que os dados são originários de produções de testes de proficiência da Cambridge que remontam ao início dos anos 1990 e que seguem sendo coletados ainda hoje. Isso significa que boa parte dos dados do EGP foi coletada em um contexto no qual estavam vigentes as orientações da T-series para o ensinoaprendizagem de inglês. Não há dúvidas de que, mesmo com o advento do QECRL (2001) e do EGP, esses documentos pautam muitas das atuais orientações acerca do ensino de inglês.

\footnotetext{
${ }^{13}$ [There are certain linguistic properties that are characteristic and indicative of L2 proficiency at each level]
} 
O English Vocabulary Profile (EVP) também é uma ferramenta disponível on-line, que se propõe a oferecer os expoentes de vocabulário empregados por aprendizes em cada um dos níveis de referência do QECRL (2001). Seus compiladores valeram-se de recursos de diversos tipos: o Cambridge English Corpus, com produções de falantes nativos; o Cambridge Learner Corpus; livros didáticos; e listas de vocabulário para testes de proficiência (EP, 2011, p. 10; 53).

É curioso observar que as listas de vocabulário citadas pelo EP (2011, p. 53), tais como Key English Test Vocabulary List (KET, 2012), estão fundamentadas nas recomendações de expoentes linguísticos presentes na T-series. Ademais, não é improvável supor que os livros didáticos, frente ao caráter genérico do QECRL (2001), também tenham se pautado, ao menos minimamente, por esses mesmos documentos. Ao final, as atuais orientações sobre o ensino de inglês parecem ser circulares, retornando à iniciativa $T$-series. Se se soma a esse quadro a já comentada seleção ad hoc de expoentes linguísticos, é plenamente possível sustentar a hipótese de que os repertórios léxicos e gramaticais presentes nos planos de trabalho de materiais didáticos podem apresentar pouca variação entre si. Além do mais, se tais materiais auxiliam no ensino-aprendizagem de inglês, espera-se que os expoentes linguísticos produzidos pelos participantes dos testes de proficiência também os empreguem para realizar as tarefas solicitadas.

O English Functions Profile (EFP), diferente dos dois anteriores, investiga o input fornecido aos estudantes de inglês por materiais didáticos e as orientações vigentes no QECRL (2001), em documentos como o CIGE (2011) e na T-series, entre outras fontes acerca do ensino e avaliação da aprendizagem de inglês. Seu principal objetivo foi oferecer descritores mais específicos acerca das funções nos níveis $C$ de aprendizagem, já que esses níveis são considerados os mais imprecisos do QECRL (2001) em função da ausência de documentos da T-series correspondentes. 


\subsection{DNR do alemão: Profile Deutsch}

No que diz respeito ao desenho dos dicionários de aprendizes do alemão à luz de um programa de trabalho, é possível afirmar que essa relação não existe. Advindo do QECRL (2001), uma série de organismos transnacionais incumbidos com o ensino do alemão apresentaram um marco de referência para o alemão denominado Profile deutsch (Profile dt, 2002), que estabelecia objetivos [Lernzielbestimmungen], competências [Kannbeschreibungen] e expoentes comunicativos [kommunikative Mittel] para os níveis de proficiência A1, A2, B1 e B2 ${ }^{14}$. Profile dt (2002) permite conhecer por nível de proficiência os expoentes comunicativos divididos em quatro âmbitos: atos de fala [Sprachhandlungen], conceitos gerais [Allgemeine Begriffe], vocabulário temático [Thematischer Wortschatz] e aspectos culturais específicos [Kulturspezifische Aspekte] (p. 140-150) ${ }^{15}$. É importante salientar que as listas respectivas só apresentam os temas e subtemas de cada âmbito. As listas específicas devem ser consultadas em um CD-ROM (Prdt 1.0) que serve como banco de dados. Há também especificações para os conteúdos gramaticais (p. 151-161). O Prdt 1.0 permite, de fato, uma série de opções de consulta. Assim, por exemplo, é possível filtrar os expoentes léxicos no vocabulário temático [Thematischer Wortschatz] tanto por nível de proficiência, como também segundo se trate de uma função de compreensão, de produção ou de compreensão e produção paralelamente, segundo uma determinada categoria morfológica, conforme se considere ou não a variação diatópica (isto é, as variantes alemã, austríaca ou suíça) e, finalmente, conforme se consulte pela estrutura de acesso temática, alfabética ascendente, descendente, etc. Ver abaixo um exemplo da tela:

${ }^{14}$ As traduções ao português objetivos, competências e expoentes comunicativos não correspondem totalmente aos termos Lernzielbestimmungen, Kannbeschreibungen e kommunikative Mittel. Por essa razão, fornecem-se os termos originais em alemão presentes no Profile dt (2002).

${ }^{15}$ As traduções ao português atos de fala, conceitos gerais, vocabulário temático e aspectos culturais específicos não correspondem totalmente aos termos Sprachhandlungen, Allgemeine Begriffe, Thematischer Wortschatz e Kulturspezifische Aspekte. Por essa razão, fornecem-se os termos originais em alemão presentes no Profile dt (2002). 
Figura 3 - Prdt 1.0.

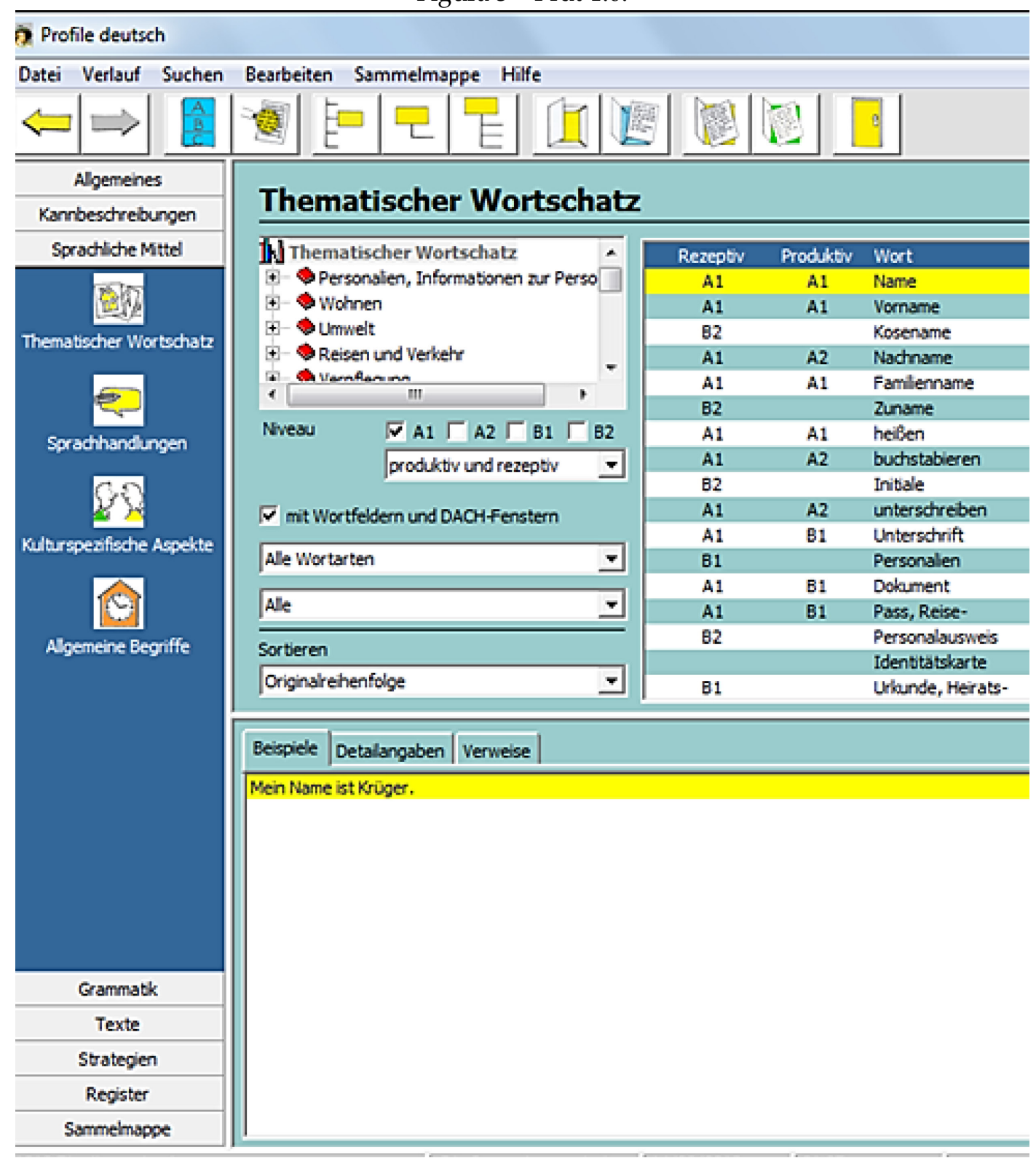

Fonte: Prdt 1.0.

Evidentemente, o vocabulário temático é um bom ponto de partida para estabelecer parâmetros que permitam aferir se os dicionários de aprendizes do alemão embasam ou não a sua macroestrutura qualitativa no Profile dt (2002). No entanto, há dois fatores aos quais é necessário atentar: Em primeiro lugar, Profile dt (2002) oferece os expoentes léxicos e gramaticais só de A1 a B2. Em segundo lugar, o programa permite que o próprio usuário alimente o banco de dados léxicos com novas palavras. 
Essas duas características dificultam muito a avaliação de dicionários de aprendizes do alemão. Por um lado, a avaliação poderia ser feita só para dicionários de iniciantes e intermediários. Por outro lado, a "abertura léxica" que Profile dt (2002) permite significa, na prática, que, mesmo no caso dos dicionários de aprendizes iniciantes e intermediários, existe uma probabilidade alta de que estes não respondam completamente às expectativas dos seus usuários. Isso se deve ao fato de que parte do vocabulário incorporado ad hoc por cada usuário do Profile dt (2002) muito provavelmente não será lematizada nos dicionários de aprendizes de alemão - que, aliás, não são muitos. Segundo Rothenhöfer (2013, p. 415), há oito dicionários de aprendizes de alemão, sendo que três deles são anteriores ao Profile dt (2002). Alguns desses possuem várias edições (como LGwtbDaF (2015), que será avaliado nesta oportunidade), mas outros não foram reeditados.

Três anos após a publicação do Profile dt (2002), foi lançada uma segunda edição (Profile dt (2005)) que considera, sim, o espectro completo de níveis de referência. No entanto, e no que concerne especificamente aos expoentes léxicos e gramaticais dos últimos dois níveis, Profile dt (2005, p. 6) afirma que "as necessidades linguísticas de aprendizes de nível avançado são difíceis de determinar"16. De facto, Profile dt (2005, p. 50) expressa claramente que "nos níveis C se prescinde de se fornecer informações sobre expoentes linguísticos"17. Dito em outros termos, os níveis C1 e C2 são explicitados só em termos de competências [Kannbeschreibungen]. Se justifica a decisão no fato de que "cada tentativa feita na etapa de desenvolvimento [sc. do Profile dt (2005)] com o objetivo de fornecer uma seleção representativa [sc. de expoentes léxicos] demonstrou logo ser subjetiva e relativamente arbitrária"18.

${ }^{16}$ [die sprachliche Bedürfnisse für Lernende mit fortgeschrittenen Niveau [sc. sind] schwer zu definieren]

${ }^{17}$ [Auf den C-Niveaus wird auf die Angabe sprachlicher Mittel verzichtet]

${ }^{18}$ [Jeder in der Entwicklungsphase unternommene Versuch einer möglichen repräsentativen Auswahl erwies sich bald als subjektiv und relativ willkürlich] 
Surpreende ler que, em relação aos expoentes léxicos dos níveis A1 e A2, na versão Profile dt (2005, p. 44), se afirma que "as decisões que permeiam a incorporação de determinadas unidades léxicas não devem ser compreendidas como soluções definitivas, mas como propostas que se podem adaptar e expandir"19. Isto significa que até por detrás das listas de vocabulário temático [Thematischer Wortschatz] (ver nota 15), bem como de conceitos gerais [Allgemeine Begriffe] desses níveis (ver nota 15), não há formalismos que permitam sustentar e/ou fundamentar tanto o leque de campos temáticos como os subcampos e os expoentes léxicos propriamente ditos (ou seja, as listas de vocabulário).

Para suprir essa sensível carência, Profile dt (2005) recorre a um dicionário de aprendizes avançados de alemão, o e-Großwörterbuch DaF 4.0 (2003) ${ }^{20}$. Dessa forma, Profile dt (2005) delega ao dicionário a tarefa de oferecer um espectro amplo de vocabulário em substituição do vocabulário temático - que, como foi mencionado acima, não pode ser estabelecido. Para enfatizar ainda mais a decisão de recorrer ao dicionário, se destaca que “o e-Großwörterbuch DaF 4.0 (2003) contém aproximadamente 33.000 entradas. Abarca, assim, o vocabulário relevante para os aprendizes de língua alemã e corresponde mais às exigências de um dicionário que almeja abranger todo o vocabulário da língua alemã" 21 .

A citação permite tirar duas conclusões. Em primeiro lugar, ao invés de se desenhar um dicionário segundo as especificações do Profile dt (2005), que seria a sequência lógica para poder chamá-lo de pedagógico (já que seu desenho estaria pautado pelas especificações lexicogramaticais de um programa de trabalho -

19 [Die Entscheidungen für bestimmte Einträge verstehen sich dabei nicht als endgültige Lösung, sondern als Vorschläge, die angepasst und erweitert werden können]

${ }^{20}$ A versão eletrônica de 2003 é anterior à versão impressa que será avaliada neste trabalho (LaGwtbDaF (2015)).

${ }^{21}$ [Das e-Großwörterbuch DaF 4.0 (2003) enthält etwa 33.000 Einträge. Es umfasst damit wichtigen Wortschatz für Lernende der deutschen Sprache und entspricht den Bedürfnissen eher als ein Wörterbuch, das versucht, den ganzen Wortschatz der deutschen Sprache zu erfassen] 
inexistente, aliás), se inverte completamente o princípio. É o dicionário que serve de banco de dados para o vocabulário dos níveis C. Em segundo lugar, a citação demostra claramente um desconhecimento em relação à própria lexicografia do alemão, já que um dicionário que almeje "abranger todo o vocabulário da língua alemã" possui uma densidade macroestrutural muito maior. Ante uma argumentação tão sui generis, teria sido mais prático oferecer o Duden Deutsches Universalwörterbuch (DUW) nas suas diversas edições - o qual conta, aliás, com uma versão gratuita na Internet ${ }^{22}$. Dessa forma, a existência de dicionários de aprendizes do alemão, ou seja, de dicionários que atendam às necessidades de aprendizagem oriundas de um programa de trabalho, constitui uma autêntica falácia.

Um último detalhe nesse sentido: Profile dt (2005, p. 78) acaba admitindo que só para os níveis A é possível oferecer uma descrição de expoentes linguísticos; para os níveis B, essa tarefa só pode ser executada "de maneira muito limitada" [im geringeren Maße], e é absolutamente impossível para os níveis C.

Em resumo, se, por um lado, só para os níveis iniciais é possível estabelecer um vocabulário temático (e, ainda assim de extensão variável, já que é expansível segundo necessidades específicas), e se, por outro lado, um dicionário de aprendizes não se fundamenta em um programa de trabalho, mas é empregado como banco de dados para o Profile dt (2005), cabe questionar-se se a designação dicionários de aprendizes pode ser usada com propriedade para aqueles dicionários que almejam auxiliar o aprendiz de alemão. É a obra lexicográfica que se deve pautar, na sua concepção e desenho, em um programa de trabalho, e não ao revés.

Frente ao exposto nesta seção, é evidente que não há como avaliar os dicionários de aprendizes do alemão e do inglês no que concerne à sua relação com o ensino-

\footnotetext{
${ }^{22}$ Disponível em: https://www.duden.de/Shop/Duden-Deutsches-Universalworterbuch-3. Acesso em: 28 abr. 2018.
} 
aprendizagem de ambas as línguas. Não há como saber se o parâmetro 1, exposto na introdução, cumpre-se nessa classe de obras.

Consequentemente, o parâmetro 3, que diz respeito às necessidades do públicoalvo, também fica comprometido, pois tais necessidades não são outras que as de ensino-aprendizagem advindas de um programa de trabalho. O máximo que se poderia avaliar em relação às necessidades do público-alvo é o potencial de auxílio das obras para tarefas de compreensão e de produção, pois a classe dos dicionários de aprendizes sempre almejou auxiliar o seu consulente a desempenhar-se em ambas as funções.

O único parâmetro que pode ser bem avaliado em dicionários de aprendizes é o respeito à norma real contemporânea. Tal indicador está contemplado pela qualidade da descrição da língua sob a perspectiva da teoria metalexicográfica. A próxima seção tratará dos critérios de avaliação atinentes a cada componente canônico que constitui um dicionário.

\section{Critérios de descrição da língua em um dicionário e norma real contemporânea}

Uma obra lexicográfica possui três componentes canônicos que a constituem: a macroestrutura, a microestrutura e a medioestrutura. A teoria metalexicográfica apresenta critérios de descrição da língua que permitem não somente oferecer um panorama coerente com a norma real, mas que permitem também incluir informações das quais se possa tirar proveito e ainda proporcionar um acesso rápido às mesmas.

A norma real é uma distinção baseada nos postulados de Coseriu (1980) e que diz respeito àquilo que os falantes realmente empregam quando usam a língua. $\mathrm{O}$ termo compreende todas as variações no que concerne ao tempo (diacronia), ao espaço geográfico (diatopia), às situações de uso (diafasia) e aos estratos socioculturais (diastratia). A norma real contemporânea, por sua vez, compreende os registros da 
segunda metade do século XX em diante; em outras palavras, no tocante ao eixo temporal, restringe-se à sincronia.

No tocante aos componentes canônicos de um dicionário, a macroestrutura corresponde ao total de palavras-entrada incluídas em um dicionário e ao critério de seleção das mesmas. A macroestrutura possui dois vieses que se integram: quantitativo e qualitativo. O viés quantitativo corresponde ao número total de lemas que conformam a macroestrutura. Até agora a metalexicografia não estabeleceu parâmetros para seu cálculo. Isso significa dizer que não há cálculos empíricos que atrelem a densidade macroestrutural a determinadas classes de dicionários. $\mathrm{O}$ viés quantitativo diz respeito também à inclusão de palavras-entrada que correspondam à norma real de uma dada língua. Ademais, analisa-se se há uma relação entre os eixos do diassistema aos quais pertencem as palavras-entrada e o tipo de informações que uma determinada obra declara fornecer. No caso de um dicionário de aprendizes, espera-se que as palavras-entrada incluídas correspondam ao menos à variável sincrônica (norma real contemporânea).

Por outra parte, o viés qualitativo se subdivide em quatro tópicos. O primeiro deles corresponde à diferenciação entre as palavras-entrada type (ou canônicas) e token (variantes de menor uso ou de menor prestígio), segundo critérios diatópicos, diaintegrativos, dianormativos, entre outros ${ }^{23}$.

O segundo tópico da macroestrutura qualitativa diz respeito à descrição de entidades categorizáveis. Conforme essa perspectiva, não é conveniente incluir nomes próprios na macroestrutura por corresponderem a entidades individuais e que não podem ser categorizadas ${ }^{24}$. Bugueño Miranda (2007a), por exemplo, recomenda a sua inclusão no Back Matter (páginas finais, situadas após a macroestrutura).

\footnotetext{
${ }^{23}$ Exemplo de variação diatópica: concreto (Brasil) / betão (Portugal). Exemplo de variação diaintegrativa: хатрu / shampoo. Exemplo de variação dianormativa: vulva / xota.

${ }^{24} \mathrm{O}$ princípio básico é não lematizar nomes próprios. Há tradições lexicográficas, como a alemã e a inglesa, no entanto, que lematizam topônimos. Neste caso, tal decisão obedece às particularidades
} 
Na mesma esteira, o terceiro tópico advoga pela não inclusão de prefixos e sufixos na macroestrutura para que o consulente não confunda o potencial de formação de unidades léxicas com o que é efetivamente realizado em uma língua. Novamente, segundo Bugueño Miranda (2007b), há preferência por incluir esse tipo de morfema no Back Matter (ver exemplos nas análises da seção 4).

O quarto tópico diz respeito ao tratamento de derivados e compostos. É possível incluir esse tipo de unidades léxicas como palavras-entrada ou como subentradas subordinadas a uma entrada principal. Não há uma orientação acerca da preferência por uma ou outra solução, embora a segunda torne a busca mais difícil para quem não está acostumado a buscar por uma unidade léxica primitiva quando não encontra um determinado derivado ou um composto. Deve-se, portanto, levar em conta a familiaridade do consulente pretenso com o agrupamento sob a forma de subentradas, as quais são muito comuns em algumas tradições, como a de língua inglesa, e nada comuns em outras, como as de língua espanhola e de língua portuguesa. Na lexicografia brasileira, o Dicionário Aurélio da Língua Portuguesa (Au, 2010), o Dicionário Houaiss da língua Portuguesa (Hou, 2009) e o Dicionário de Usos do Português do Brasil (DUPB, 2002) optam pela solução de estrutura lisa. Novamente, a única exceção é o Grande Dicionário Sacconi da Língua Portuguesa (Sacc, 2010), que optou por uma opção de nicho léxico. Assim por exemplo, s.v. enobrecer são lematizados os derivados enobrecedor e enobrecimento.

O segundo componente canônico a ser comentado nesta seção é a microestrutura, que corresponde às informações fornecidas em cada verbete. Este

ortográficas que esses nomes apresentam. No caso da lexicografia brasileira, nem o Dicionário Aurélio da Língua Portugues(Au, 2010) nem o Dicionário Houaiss da língua Portuguesa (Hou, 2009), nem o Dicionário de Usos do Português do Brasil (DUPB, 2002) lematizam esse tipo de nomes. Uma única exceção está constituída pelo Grande Dicionário Sacconi da Lingua Portuguesa (Sacc, 2010), que lematiza topônimos, como Albânia e nomes próprios, como Brás Cubas. 
componente também apresenta dois vieses, um relacionado à qualidade das informações e outro à organização das mesmas.

No tocante à qualidade das informações, Bugueño Miranda e Farias (2008, 2013) defendem que as mesmas devem ser discretas, ou seja, devem ser manifestações da norma real (cf. página anterior para uma definição do termo); e também discriminantes, isto é, devem ser úteis para o consulente pretenso conforme as tarefas de compreensão e/ou de produção que este precisa executar. Sobre esse ponto em particular, é necessário ter em mente que a utilidade de uma informação em um dicionário de aprendizes também está diretamente relacionada com a língua materna do potencial consulente. São inegáveis as influências que a língua materna exerce sobre a nova língua que se está aprendendo e vice-versa. Não é à toa que se criam corpora de aprendizes que, em cada dado fornecido, indicam a língua materna de quem o produziu. Os dicionários de aprendizes, no entanto, se dirigem a todo e qualquer indivíduo que está em processo de aprendizagem de uma língua - um público demasiado heterogêneo para que se possam fornecer informações úteis para todos os potenciais consulentes.

O viés qualitativo da microestrutura influencia diretamente o tipo de informações que serão fornecidas e como as mesmas serão organizadas. Conforme Bugueño Miranda (2009), cada verbete pode fornecer dados acerca da palavra-entrada no tocante ao seu significante (ortografia, pronúncia, classe morfológica, valência verbal, etc.) e ao seu significado (definição, exemplos, marcas de uso e sinônimos, etc.). Esses dois conjuntos de informação são denominados comentário de forma e comentário semântico, respectivamente, e, juntos, constituem o programa constante de informações (pci) da microestrutura. Naturalmente, dependendo da classe morfológica e de outras propriedades inerentes a cada unidade léxica, alguns verbetes manifestarão umas e não outras informações. Além disso, cada tipo de informação incluída está atrelado à função de compreensão, produção ou ambas. A definição, por 
exemplo, serve para a compreensão; as colocações, para a produção; e os exemplos podem auxiliar tanto na compreensão como na produção.

O último componente canônico que cabe mencionar é a medioestrutura, que consiste no sistema de remissões de um dicionário. Esse componente canônico está diretamente relacionado com o tratamento type/token da macroestrutura, pois é por meio de uma remissão que se indica uma forma type a partir de uma forma token.

\section{Análise dos dicionários de aprendizes}

Os dicionários avaliados são Cambridge Advanced Learner's Dictionary (CALD, 2013), para o inglês, e Langenscheidt Großwörterbuch Deutsch als Fremdsprache (LGwtbDaF, 2015), para o alemão. A escolha de quantos e quais dicionários seriam avaliados se deveu a três fatores. Em primeiro lugar, o espaço não permitia mais do que uma avaliação exaustiva por tradição lexicográfica. Em segundo lugar, as duas obras escolhidas se definem como dicionários para avançados. As ponderações feitas no texto demonstram que não há, no entanto, parâmetros para a sua elaboração. Em terceiro lugar, no caso específico do inglês, assume-se que CALD (2013) é uma projeção "lógica" do English Profile (2011), já que este documento emana da própria editora Cambridge; a escolha se deveu também ao fato de que a Cambridge University Press edita múltiplos materiais para o ensino de inglês como língua estrangeira. No que tange ao alemão, LGwtbDaF (2015) é recomendado pelo próprio Profile Deutsch (2005) como uma obra de referência que satisfaria as necessidades léxicas dos utilizadores deste documento.

\subsection{Análise do Cambridge Advanced Learner's Dictionary (CALD, 2013)}

Em relação à definição macroestrutural quantitativa, uma análise de 4 intervalos lemáticos de duas páginas cada um, multiplicados pelo número de páginas da macroestrutura do CALD (2013) resultou em 69.692 lemas (para esse cálculo, 
consideraram-se as famílias léxicas também). No Front Matter, não há informações específicas acerca dos critérios de seleção de entradas. As únicas informações presentes permitem deduzir que os redatores do CALD (2013) se ativeram à norma real por meio do trabalho com corpora, pois se propõem a descrever "como o inglês funciona e o que as pessoas realmente dizem ou escrevem" 25 e registrar "quais maneiras de dizer as coisas são mais comuns" ${ }^{26}$ (CALD, 2013, p. ix).

Ao contrário de outros expoentes da tradição inglesa, como o OALD (2010), por exemplo, não há informações acerca do emprego de um vocabulário de definidores. Tampouco há indicações da frequência das unidades léxicas incluídas. A proposta do CALD (2013) é diferente porque se atrela aos dados obtidos por meio do English Vocabulary Profile (EP, 2011) para fornecer indicações dos níveis de referência nos quais se usam determinadas unidades léxicas (e, em verbetes polissêmicos, cada acepção). Entretanto, nota-se que a inclusão de parte significativa das unidades léxicas que constituem a macroestrutura não partiu de dados do EP (2011). Sobre esse particular, é curiosa a defesa dos redatores do CALD (2013) ao afirmarem que "se nenhum nível é assinalado, isso significa que é acima do nível C2. Você pode usar essa informação para decidir quais palavras precisa priorizar na sua aprendizagem de vocabulário" 27 . Em primeiro lugar, a escala empregada (A1-C2) não prevê níveis acima de $C 2$, mas, sim, culmina nesse nível. Frente a esse fato e à falta de informações mais precisas sobre em que consistem tais informações "extra níveis de referência", pode-se apenas inferir que se tratam de elementos presentes no Cambridge English Corpus - ferramenta que, aliás, é citada como fonte de consulta para a compilação do CALD (2013, p. ix). Os redatores não informam, no entanto, quais foram os demais critérios empregados para a seleção e inclusão dessas informações no CALD (2013).

\footnotetext{
${ }^{25}$ [how English Works and what people actually say or write]

${ }^{26}$ [which ways of saying things are more common]

${ }^{27}$ [if no level is shown, this means that it is above C2 level. You can use this information to decide which words you need to prioritize in your vocabulary learning]
} 
Em segundo lugar, a coexistência de unidades léxicas efetivamente usadas por estudantes de níveis A1 a C2 (provenientes dos dados do EP (2011)) e de outras unidades léxicas incluídas (aparentemente) por um critério de frequência ("extra níveis de referência") leva-nos a conjeturar que o CALD (2013), na verdade, poderia ser caracterizado como um dicionário "2 em 1": por um lado, inclui-se aquilo que os aprendizes de níveis A1 a C2 empregam - uma tentativa de aproximar-se do conceito de dicionário pedagógico, apesar das diversas ressalvas já discutidas neste trabalho sobre esse conceito; por outro lado, inclui-se também um conjunto de outras unidades léxicas aparentemente usadas no inglês (já que os redatores mencionam que se empregaram dados do Cambridge English Corpus). Em outras palavras, uma parte do CALD (2013) corresponderia a um “dicionário de aprendizes", enquanto que a outra parte seria algo que se aproximaria a um "dicionário de uso" (cf. BORBA (2015) sobre as características dessa classe de obras). De acordo com a citação acima, os redatores julgam pertinente disponibilizar informações "extra níveis de referência" para que os aprendizes possam eleger o que é relevante para si de acordo com as suas necessidades comunicativas, sem que tenham de recorrer a um dicionário de uso para falantes nativos, por exemplo. Contudo, a falta de informações sobre os critérios de seleção e inclusão dos elementos "extra níveis de referência" não nos permite avaliar se tais elementos seriam realmente pertinentes ao público almejado.

No que concerne à macroestrutura qualitativa, o CALD (2013) se destaca pelo minucioso tratamento type/token atribuído a variantes diafásico-diastráticas, como “boffin [...] mainly UK informal" e "bohemian [...] (informal boho)" (CALD, 2013, s.v.); variantes diatópicas, como "boerewors [...] South African English", "bogie [...] Indian English”, "bogan [...] Australian English informal" e "bodywarmer [...] UK (US vest)"; e variantes ortográficas, como “bogeyman [...] (also bogyman, US also boogeyman)" e “bolshy (also bolshie)".

É interessante também a lematização de diversos casos de combinatórias léxicas sob a forma de entradas independentes. Os verbetes boiler suit e the silver screen são 
exemplos disso. Tal decisão parece ser acertada porque, por um lado, não há a necessidade de buscar dentro dos verbetes, tal como ocorre com outras obras, e, por outro lado, porque converge com a ordem em que os constituintes das combinatórias progridem durante a leitura, facilitando a busca para o consulente.

Contudo, constatou-se que também há um inchaço macroestrutural. Em primeiro lugar, o CALD (2013) inclui afixos, tais como contra-, dis-, -able e -ence. Questionamos a pertinência da inclusão destes e de outros afixos, considerando que, conforme mencionado na seção 3, podem conduzir o consulente a cometer erros. CALD (2013, s.v. contra-) menciona que esse sufixo significa "against or opposite". O lema seguinte é contraband, e é evidente que não há como estabelecer uma relação de oposição entre contra- e band (ver acepções s.v. band). No caso do sufixo dis-, o dicionário explicita que se usa "added to the front of some words to form the opposite" (CALD, 2013, s.v. dis-). O aprendiz, por sua vez, não tem como saber quais são aquelas “algumas palavras". Além disso, se esse aprendiz é falante de português ou de espanhol como língua materna, por exemplo, poderia perfeitamente concluir, por analogia ao português ou ao espanhol desmotivar, que o antônimo de motivate é *dismotivate, quando, na verdade, é demotivate.

Em segundo lugar, há uma grande variedade de elementos tratados como type/token que não precisariam estar presentes em um dicionário que se dirige a aprendizes de níveis intermediário superior e avançado ${ }^{28}$. Mais especificamente, os verbos com pretérito irregular (CALD, 2013, s.v. put, swam, taught), particípios irregulares (CALD, 2013, s.v. put, swum, taught) e plurais irregulares (CALD, 2013, s.v. children, feet, men) são elementos que já não seriam mais pertinentes para esse perfil de consulente.

\footnotetext{
${ }^{28}$ Não é possível compreender por que o dicionário não usa a escala do QECRL (2001) - a qual, aliás, é empregada para distinguir acepções. Seria mais óbvio afirmar que se dirige a quem está nas etapas B2, $\mathrm{C} 1$ e $\mathrm{C} 2$ de aprendizagem.
} 
Em terceiro lugar, nomes próprios, como Bollywood e Shrove Tuesday, e siglas, como BMI e SIDS (CALD, 2013, s.v.), também podem ser encontrados na macroestrutura. Novamente, defendemos que sua inclusão constitui um inchaço macroestrutural e que seria mais apropriado incluí-los em uma seção à parte no dicionário.

Ainda no tocante à macroestrutura qualitativa, e conforme se pode conferir por meio do verbete sick, o CALD (2013) adotou uma solução polissêmica. No exemplo citado, no qual co-ocorrem manifestações de sick como adjetivo, verbo e substantivo, há uma divisão interna no verbete, com um espaço reservado a cada classe morfológica envolvida.

Finalmente, o CALD (2013) lematiza famílias léxicas sob a forma de run-onentries, em uma estrutura de ninho léxico; em outras palavras, as famílias léxicas são "entradas subordinadas a uma entrada principal que não recebem uma definição" e, no caso específico dos ninhos léxicos, há uma quebra da progressão alfabética (BORBA, 2016, p. 7). Um exemplo disso pode ser encontrado s.v. bold: “bold [...] •boldly [...] •boldness [...]". As informações que o dicionário fornece sobre os membros de uma família léxica se restringem ao comentário de forma (pronúncia e classe gramatical) e, em alguns casos, há também um exemplo.

No que concerne à microestrutura, o programa constante de informações é extenso, pois são fornecidos diversos tipos de segmentos informativos. O comentário de forma pode conter: a) representação ortográfica (bogeyman); b) transcrição fônica com variantes norte-americanas, separação silábica e marcação da sílaba tônica (/'bəひ.gi.mæn/ US /'bov-/); c) propriedades morfossintáticas - classe morfológica (adj, verb, noun), transitividade do verbo ([T], [l], [I or T]), natureza contável ou não contável do substantivo ([C] ou [U]), formas irregulares dos verbos no passado, no particípio e no gerúndio (put [...] [present tense putting, past tense and past participle put]), flexão de número 
irregular (sheep [...] [plural sheep]), pluralia tantum ${ }^{29}$ (in-laws noun [plural]) e singularia tantum $^{30}$ (scan [...] noun $\mathbf{1}[\mathrm{S}]$ ); d) variantes ortográficas ((also bogyman, US also boogeyman)).

Todos os segmentos informativos do comentário de forma auxiliam em tarefas de produção. Alguns deles, quando estão atrelados às acepções específicas de verbetes polissêmicos, auxiliam a distinguir uma acepção de outra. É o caso de certas propriedades morfossintáticas, como a classe morfológica, a transitividade do verbo, a natureza contável ou não contável do substantivo e os pluralia tantum e os singularia tantum.

O comentário semântico, por sua vez, pode conter: a) paráfrase explanatória; b) exemplo; c) em alguns casos, sinônimos (serviette $\rightarrow$ Synonym napkin) e antônimos (sincere $\rightarrow$ Opposite insincere); d) marca de uso com distinção diatópica e diafásicodiastrática (ver exemplos acima na macroestrutura qualitativa); e) distinguidores semânticos para separar as acepções de verbetes muito polissêmicos (sick [...] ILL [...] vomıt [...] UNPLEASANT [...]); f) indicação do nível do QECRL (2001) em que o uso de uma acepção já está consolidado segundo o EP (2011); g) eventuais ilustrações (frying pan); h) colocações (sorry [...] 6 sorry sight/state/tale); i) coligações (infra dig [...] [after verb]); j) fraseologias (sorry [...] 2 feel sorry for yourself); k) fórmulas ritualísticas (sorry [...] 3 I'm sorry to say).

Os segmentos informativos que auxiliam na compreensão são a paráfrase explanatória, as fraseologias e as ilustrações inseridas junto aos verbetes. As colocações, por outro lado, se enquadram melhor na função de produção em razão da absoluta aleatoriedade na seleção do colocado (embora sejam relativamente acessíveis

\footnotetext{
${ }^{29}$ Unidades léxicas que se flexionam somente no plural. Cf. Moura Neves (2003, s.vs. singularia tantum e pluralia tantum) e Cunha e Cintra (2008, p. 201).

${ }^{30}$ Unidades léxicas que se flexionam somente no singular. Cf. Moura Neves (2003, s.vs. singularia tantum e pluralia tantum) e Cunha e Cintra (2008, p. 201).
} 
em termos de compreensão). Já os demais segmentos informativos do comentário semântico auxiliam tanto na compreensão como na produção.

Faz-se necessário comentar que o segmento informativo dos exemplos possui várias incumbências. Além de serem auxiliares tanto na compreensão como na produção, delega-se a esse segmento informativo a tarefa de indicar colocações (sick [...] 1 [...] The old woman fell/took/was taken sick (=became ill) while she was away and had to come home) e coligações (shy [...] 1 [...] Children are often shy of/with people they don't know).

Algumas informações são fornecidas também sob a forma de pós-comentários de forma e pós-comentários semânticos. Os quadros intitulados "Word partners" indicam padrões colocacionais, como s.v. atmosphere. Os quadros intitulados "Common mistake" indicam erros das mais diversas naturezas e encontrados no Cambridge Learner Corpus, como coligações (s.v. listen), representação ortográfica (s.v. sincerely), pragmática (s.v. sincerely), entre outros. Os quadros "Usage" e "Other ways of saying" apresentam diferenças entre sinônimos (s.v. listen, station). Há ainda quadros "Note", com informações a nível pragmático (s.v. someone).

Além dos quadros, as seções "Phrasal verbs" e "Idioms" também constituem seções separadas - embora seja possível encontrar fraseologias e fórmulas ritualísticas sob a forma de acepções.

\subsection{Análise do Langenscheidt Großwörterbuch Deutsch als Fremdsprache (LGwtbDaF, 2015)}

No que se refere à definição macroestrutural, elegeram-se também quatro intervalos lemáticos de uma página cada um. Calculando o promédio de lemas dos intervalos multiplicado pelo número de páginas do dicionário, pode-se afirmar que a densidade macroestrutural de LGwtbDaF (2015) é de 33.410 lemas, aproximadamente ${ }^{31}$. A essa quantidade devem acrescentar-se os 30.000 compostos e

\footnotetext{
${ }^{31}$ Essa quantidade coincide com a afirmação feita em Profile dt (2005) sobre este particular.
} 
derivados (subentradas, ou run-on-entries) que o dicionário afirma registrar também. A soma das duas quantidades atinge cerca de 64.000 lemas.

No que diz respeito às cifras, e na mesma esteira das afirmações que se fazem no Profile dt (2005) de que não há orientações sobre quantos e quais expoentes léxicos um aprendiz avançado precisa, uma alta densidade macroestrutural não é sinônimo de qualidade nem de funcionalidade. LGwtbDaF (2015) afirma no Front Matter que há um vocabulário central para o alemão de 5500 lemas, que constitui o conjunto de uma interseção entre vários vocabulários básicos e complementares. Esse vocabulário central corresponde ao vocabulário estabelecido pelo Instituto Goethe, chamado de Zertifikatwortschatz. LGwtbDaF (2015) complementa esse vocabulário central com listas de frequência do Corpus de Referência do Alemão, o Deutsches Referenzkorpus (DeReKo) do Institut für Deutsche Sprache, assim como também com as listas do projeto Vocabulário do Alemão, o Deutscher Wortschatz, da Universidade de Leipzig. Desta forma, LGwtbDaF (2015) almeja estabelecer as 4000 palavras mais frequentes que seriam importantes para o aprendiz.

Möhring e Wallner (2013) fizeram uma pesquisa sobre listas de vocabulário básico oriundas de corpora e confrontadas com o Profile dt (2005) e concluíram que há uma falta de congruência entre os resultados obtidos por critérios estatísticos, empregando corpora, e os que se obtêm baseados em vocabulários temáticos, que é o procedimento empregado pelo Profile dt (2005). Dessa forma, a nossa hipótese sobre a falta de fundamentação para o estabelecimento de expoentes léxicos em Profile dt (2005) se confirma, mas se corrobora também que a densidade macroestrutural de LGwtbDaF (2015) tampouco oferece, prima facie, uma maior fiabilidade.

No tocante à definição macroestrutural qualitativa, constata-se que o LGwtbDaF (2015) lematiza afixos, uma classe de elementos que não trazem proveito algum para o consulente, já que nenhum afixo pode ser combinado livremente para 
formar novas unidades léxicas ${ }^{32}$. Assim, por exemplo, LGwtbDaF (2015) lematiza o prefixo $a b$, que possui, dentre outros, um valor de negação, e que está presente em unidades léxicas como abservieren "dispensar", absagen "recusar", e abberufen "demitir". No entanto, não existe no alemão a opção *abfunktionieren "deixar de funcionar", muito embora no sistema da língua essa opção seja potencialmente possível. Os dicionários só podem tratar fatos de norma, não de sistema (cf. Coseriu (1992) para esse conceito).

Em relação à distinção type/token, ou seja, a necessária distinção entre formas preferenciais e secundárias ou não preferenciais, LGwtbDaF (2015) aplicou consequentemente esta distinção a casos de flexão irregular dos verbos, como s.v. dürfte "[...] $\rightarrow$ dürfen"; à variação ortográfica, como s.v. "Handicap $[. ..] \rightarrow$ Handikap"; à variação fonológica, como s.v. Bẹr-ser-ker, Ber-sẹ-ker; e ainda à variação diatópica, como s.v. mürb "besonders süddeutsch $\mathrm{A} \rightarrow$ mürbe".

Uma das dimensões da definição macroestrutural qualitativa diz respeito à adoção de uma solução polissêmica ou homonímica. Emprega-se a expressão solução, já que o lexicógrafo cria um único bloco ou decupa em dois ou mais verbetes, unidades léxicas que, pela sua condição polissêmica ou homonímica, deveriam aparecer em um único bloco (em se tratando de um caso de polissemia), ou em vários blocos (em se tratando de colisões homonímicas) (para mais detalhes, cf. BUGUEÑO MIRANDA (2016)).

LGwtbDaF (2015) tem a tendência de dotar uma solução homonímica. No entanto, não é possível estabelecer um padrão para a separação de dürfen ${ }^{1}$, dürfen ${ }^{2}$; folgen $^{1}$, folgen ${ }^{2}$; hängen ${ }^{1}$, hängen ${ }^{2}$, considerando que os três verbos constituem unidades léxicas polissêmicas. Já para os substantivos, o critério é o etimológico, como s.v. Kuli Kuli² Partikel $^{1}$, Partikel ${ }^{2}$; Plastik ${ }^{1}$, Plastik $^{2}$.

\footnotetext{
${ }^{32}$ Ver as observações feitas para o mesmo tópico nos dicionários do inglês, particularmente o CALD (2013).
} 
No âmbito microestrutural, a base da análise é a avaliação do programa constante de informações (pci). LGwtbDaF (2015) apresenta um pci complexo. No âmbito do comentário de forma, há os seguintes segmentos informativos: a) representação ortográfica (insbesondere, insbesondre); b) separação silábica (lang • sam) e, segundo a categoria morfológica, flexão de caso (Subjekt das <-(e)s, -e>), flexão de comparativo e superlativo $(m u s \bullet k u \bullet l o ̈ s$ ADJEKTIV meist <muskulöser, muskulösest>), posição atributiva ou predicativa do adjetivo (per•plex ADJEKTIV meist prädikativ; gesprochen) e tempos e modelos da conjugação (schä•di•gen V/T (schädigte, hat geschädigt)). Sem dúvidas, esse conjunto de informações corresponde ao que Bugueño Miranda e Farias $(2008,2013)$ denominam de informações discretas e discriminantes, já que se tratam de fatos de norma real dos quais o consulente tira um proveito efetivo.

Para efeitos de análise, é recomendável distinguir entre segmentos informativos referentes à compreensão e segmentos informativos referentes à produção.

De importância primária para a compreensão é a paráfrase explanatória, evidentemente. EmBugueño Miranda e Farias (2013), salienta-se a este respeito que a redação de paráfrases sempre oferecerá resultados heterogêneos, já que - é fundamental reconhecer - há palavras difíceis de definir. O emprego de um vocabulário de definidores ajuda nesse sentido, mas, como salientam Herbst e Klotz (2003, p. 48), "não seria possível elucidar semanticamente e de maneira satisfatória todas as significações [sc. empregando unicamente um vocabulário de definidores] [...]"33. Em termos gerais, as paráfrases de LGwtbDaF (2015) estão bem estruturadas e são de fácil compreensão, como s.v. Fahrstuhl "eine Kabine, mit der Personen in einem Gebäude nach oben und unten transportiert werden" [elevador "uma cabine na qual as pessoas são transportadas para cima e para baixo em um prédio"]. No caso de substantivos e adjetivos abstratos, os resultados não são tão bons, porque essas classes

33 [es dürfte kaum möglich sein, alle Bedeutungen [...] im Rahmen [sc. eines begrenzten Definitionswortschatzes] semantisch befriedigend zu erklären [...]] 
de unidades léxicas são difíceis de definir. É o que ocorre s.v. eitel: "<ein Mensch> so, das sehr bewundert werden will und sich daher in besondere Weise benimmt oder kleidet" [vaidoso "<ser humano> que deseja ser admirado e, por isso, se veste e se comporta de uma forma particular"]. No caso dos verbos, não se pode separar a geração de paráfrases da explicitação da valência. Um exemplo é o verbo geben. Assim, por exemplo, as acepções vão precedidas de distinguidores semânticos [Wegweiser]: "ge•ben $[. .$.$] 『 V/T >$ einer Person; Sache, Geld ${ }^{1}$ jemandem etwas geben etwas in die Hände oder in Nähe einer Person legen oder stellen, sodass sie es bekommt" ["dar [...] - V/T a uma pessoa; uma coisa, dinheiro ${ }^{1}$ dar algo para alguém botar algo nas mãos ou perto de uma pessoa, de modo que o receba"]. Esses distinguidores cumprem uma dupla função: agrupam acepções e explicitam a forma de "preencher" os actantes einer Person [a uma pessoa] (dativo) e Sache, Geld [coisa, dinheiro] (objeto direto). Além disso, cada acepção vai acompanhada de exemplos ("jemandem ein Buch geben" ["dar um livro para alguém"]; "einem Kind ein Glas Milch geben” [“dar um copo de leite para uma criança"]). Tanto os distinguidores semânticos como a explicitação da valência (jemandem etwas geben [dar algo para alguém]), assim como os exemplos, são mecanismos de recursividade ${ }^{34}$ que complementam a elucidação da paráfrase.

LGwtbDaF (2015) oferece outros dois segmentos para tarefas de compreensão: sinonímia e substituição ostensiva. Em relação à sinonímia, ela se emprega quando o sinônimo é uma designação mais frequente, como s.v. Glace “[...] $\approx$ Speiseeis, Eiscreme" ${ }^{\prime 35}$. Já a substituição ostensiva é particularmente útil quando, por efeito do anisomorfismo linguístico (cf. ZGUSTA (1971)), um número de unidades léxicas de uma língua recebe uma mesma designação, enquanto que o mesmo não acontece em

\footnotetext{
${ }^{34}$ Recursividade é o termo encontrado para assinalar uma tendência da lexicografia alemã como um todo de "repetir" um dado tipo de informação ao longo de vários segmentos. No caso descrito acima, os padrões de valência aparecem explicitados não somente na marcação da valência do verbo, mas nos exemplos também.

${ }^{35}$ Para as três designações do alemão, o português emprega unicamente sorvete.
} 
outra(s) língua(s). Os verbetes Deckel e Feder são dois ótimos exemplos de um emprego eficiente de substituição ostensiva.

Em relação aos segmentos para a produção, a explicitação da valência, discutida anteriormente e exemplificada com o verbo geben, cumpre eficientemente com a função de fornecer ao consulente todas as informações necessárias para calcular corretamente o emprego do verbo. Um outro segmento de dupla função é a sinonímia, como s.v. Marihuana "[...] $\approx$ Haschisch $[. .]$.$" . O indicador \approx$ assinala que a equivalência é aproximada. Um terceiro segmento é a antonímia. É necessário destacar que as opções antonímicas estão atreladas a acepções específicas dentro do verbete, como s.v. heben “[...] 3 etwas hebt etwas [...] etwas verbessert, steigert etwas [...] $\boxminus$ senken [...]" [s.v. levantar "[...] 3 algo levanta algo [...] algo melhora, potencializa algo [...] $\boxminus$ afundar $\left.[\ldots]^{\prime \prime}\right]$.

Colocações e coligações merecem um comentário à parte. LGwtbDaF (2015) apresenta informações abundantes em relação a estes fenômenos léxicos. Os padrões colocacionais são apresentados dentro de parênteses triangulares $(<>)$ e atrelados a uma acepção específica, como s.v. empfangen "[...] 1 [...] etwas (von jemandem) bekommen <ein Geschenk, ein Telegramm, einen Brief, einen Auftrag empfangen> 2 [...] jemandem (irgendwie) begrüßen <jemanden freundlich, höflich, herzlich, kühl empfangen> [...]" [s.v. receber "[...] 1 [...] obter (de alguém) algo <um presente, um telegrama, uma carta, receber uma tarefa> 2 [...] cumprimentar (de alguma forma) alguém <receber alguém de forma amistosa, cortês, cordial, fria> [...]"].

Em relação aos padrões coligacionais, são oferecidas também informações muito úteis, como s.v. beinahe "[...] beinahe und fast können ein Verb modifizieren, nahezu jedoch nicht $[\ldots]^{\prime \prime 36}$.

\footnotetext{
${ }^{36}$ Em razão do anisomorfismo linguístico entre o português e o alemão, não é possível traduzir o verbete beinahe, já que, onde o alemão tem três expressões, o português tem somente uma (quase).
} 


\section{Considerações finais}

À luz das premissas estabelecidas nas páginas iniciais, a análise feita tanto dos documentos elaborados ex professo para o ensino-aprendizagem do inglês e do alemão, assim como dos dicionários de aprendizes respectivos para ambas as línguas, demonstram uma inquietante convergência.

Em primeiro lugar, nem o English Profile (2011) nem o Profile Deutsch (2005) oferecem coordenadas suficientemente claras na sua constituição para que se possa depreender deles o conjunto de expoentes que permitiria desenhar um dicionário de aprendizes realmente funcional para cada uma das línguas. No English Profile (2011), a hesitação em apresentar de forma clara como se extraem os expoentes léxicos levanos a pensar que se agiu de uma maneira um tanto circular. Um documento como o English Profile (2011) é (ou deveria ser) um documento norteador, ou seja, ancorado em premissas de fundamentação sólida. A sua leitura crítica revela, no entanto, que parece estar estruturado sobre a base de fatos consumados, mas não necessariamente fundamentados. No caso do Profile deutsch (2005), a sua análise é ainda mais desconcertante, já que não somente replica um viés de concepção muito parecido ao seu homólogo inglês, mas também acaba reconhecendo que não consegue fundamentar as suas decisões teórico-metodológicas além dos níveis iniciais (A1-A2). Para nós, é evidente que a constituição desses documentos adoece de sérias limitações, mascaradas em subterfúgios tais como que as necessidades dos beneficiários finais de todo o processo de ensino-aprendizagem de uma língua estrangeira são específicas e, por isso, tais documentos deveriam ter uma flexibilidade no preenchimento dos expoentes linguísticos dos seus diferentes níveis. Dito em outros termos, esses documentos oferecem um consenso mínimo e deixam muito em aberto.

No que tange aos dicionários, e na esteira da definição de Hartmann e James (2001), cabe se questionar em que medida os dicionários de aprendizes são realmente dicionários pedagógicos, ou seja, desenhados para servir de auxílio no processo de 
ensino-aprendizagem de uma língua estrangeira. Constatou-se que os documentos norteadores a partir dos quais deveriam ser desenhados estão longe de oferecer o conjunto de expoentes linguísticos que permita tal desenho. No caso do alemão, o problema é ainda mais grave, pois se delega a um dicionário a tarefa de resolver o que o próprio documento não consegue estabelecer. Constitui-se assim uma viciosa circularidade.

A nossa análise permitiu constatar que os dois dicionários avaliados são bons na medida em que espelham a norma real de cada uma das línguas que processam lexicograficamente; são bons porque acompanham o estado da arte da linguística, oferecendo, por exemplo, um generoso espaço para a dimensão combinatória do léxico; são bons porque transpõem para a obra lexicográfica pilares fundamentais do trabalho com corpora, como a possibilidade de fornecer farta exemplificação. Contudo, a sua bondade é oriunda da linguística e de áreas conexas, não dos documentos norteadores de ensino-aprendizagem de línguas estrangeiras.

Summa sumarum: da tríade que constitui a premissa da pesquisa, só foi possível avaliar positivamente o espelhamento da língua em uso. Isso é uma verdade. Na nossa opinião, é um mito pensar que os dicionários avaliados sejam o resultado da transposição de orientações advindas de documentos norteadores de ensinoaprendizagem de línguas estrangeiras. Apelando a um neologismo da moda, os dicionários avaliados não dialogam com os documentos supracitados. E note-se o seguinte: para nenhuma das duas línguas.

\section{Referências Bibliográficas}

Au. FERREIRA, A. B. H. Dicionário Aurélio da Língua Portuguesa. Curitiba: Editora Positivo, 2010. 2272 p.

BORBA, L. C. Dicionários de uso na lexicografia hispânica: análise do DUE, DUEAE, DEA e DiClave. In: XI SEPESQ, 2015, Porto Alegre. Sustentabilidade, ciência e ética: responsabilidade ambiental, social, econômica e cultural / XI Semana de Extensão, 
Pesquisa e Pós-graduação. Porto Alegre: UniRitter, 2015b. Disponível em: https://www.uniritter.edu.br/files/sepesq/arquivos trabalhos/3612/776/870.pdf.

Acesso em: 25 fev. 2018.

BORBA, L. C. Lexicografia e ensino: o auxílio dos dicionários gerais de língua espanhola disponíveis na internet. Linguasagem, São Carlos, v. 25, n. 1, 2016. Disponível em: http://www.linguasagem.ufscar.br/index.php/linguasagem/issue/view/8/showToc. Acesso em: 30 abr. 2017.

BORBA, L. C. Panorama da Lexicografia Hispânica. Subsídios para o professor de ELE. Saarbrücken: Novas Edições Acadêmicas, 2017. 108 p.

Breakthrough. TRIM, L.M. Breakthrough. s/l, s/d (manuscrito não publicado oficialmente). Disponível em: http://www.englishprofile.org/the-cefr/further-reading. Acesso em: 20 mar. 2018.

BUGUEÑO MIRANDA, F. V. O que é macroestrutura no dicionário de língua? In: ISQUERDO, A. N.; ALVES, I. M. (org.). As ciências do léxico: lexicologia, lexicografia e terminologia. São Paulo: Humanitas, v. 3, p. 261- 272, 2007a.

BUGUEÑO MIRANDA, F. V. O dicionário como reflexo da língua. Expressão, Santa Maria (UFSM), v. 11, n. 1, p. 97-105, $2007 b$.

BUGUEÑO MIRANDA, F. V. Sobre a microestrutura em dicionários semasiológicos do alemão. Contingentia, Porto Alegre, v.4, n.2, p. 60-72, 2009. Disponível em: http://seer.ufrgs.br/index.php/contingentia/article/view/11414. Acesso em: 26 mar. 2018.

BUGUEÑO MIRANDA, F. V. As soluções polissêmicas e homonímicas em dicionários semasiológicos. Trama, Marechal Cândido Rondon, v. 12, n. 24, p. 121-153, 2016. Disponível em: http://e-revista.unioeste.br/index.php/trama/article/view/11424. Acesso em: 26 mar. 2018.

BUGUEÑO MIRANDA, F. V.; FARIAS, V. S. O ensino de português e os dicionários escolares: um segmento informativo da microestrutura para fins de produção textual. Polifonia, Cuiabá, v. 14, n. 15, p. 1-14, 2008. Disponível em: http://periodicoscientificos.ufmt.br/ojs/index.php/polifonia/article/view/1032. Acesso em: 26 mar. 2018. 
BUGUEÑO MIRANDA, F. V.; FARIAS, V. S. Proposta de um modelo de avaliação de dicionários escolares de Língua Portuguesa. In: XIV SEMINÁRIO NACIONAL DE LETRAS E LINGUÍSTICA E IV SEMINÁRIO INTERNACIONAL DE LETRAS E LINGUÍSTICA, 2013, Uberlândia. Anais do SILEL. Uberlândia: EDUFU, 2013. v. 3., p. 01-20.

CALD. CAMBRIDGE. Cambridge Advanced Learner's Dictionary. Cambridge: Cambridge University Press, 2013.

CIGE. BRITISH COUNCIL, EAQUALS. A Core Inventory for General English. United Kingdom: British Council, 2011. Disponível em: http://englishagenda.britishcouncil.org/continuing-professional-development/cpdteacher-trainers/british-council-eaquals-core-inventory-general-english. Acesso em: 26 mar. 2018.

COD. Concise Oxford Dictionary of the English Language. Oxford: OUP, 2010. 1856 p.

COSERIU, E. Lições de linguística geral. Rio de Janeiro: Ao Livro Técnico, 1980.

COSERIU, E. Einführung in die Allgemeine Sprachwissenschaft. Tübingen: Francke, 1992.

CUNHA, C.; CINTRA, L. Nova Gramática do Português Contemporâneo. Rio de Janeiro: Lexikon, 2008.

DContLP. GEIGER, P. (org.). Novíssimo Aulete Dicionário contemporâneo da língua portuguesa. Rio de Janeiro: Lexikon , 2011. 1456 p.

DUPB. BORBA, F. S. Dicionário de Usos do Português do Brasil. São Paulo: Ática, 2002. 1673 p.

DUW. Duden Deutsches Universalwörterbuch. Mannheim: Bibliographisches Institut, 2003.

ENGELBERG, S.; LEMNITZER, L. Lexikographie und Wörterbuchbenutzung. Tübingen: Saiffenburg, 2009. 327 p.

EP. UNIVERSITY OF CAMBRIDGE. English Profile. Introducing the CEFR for English. Version 1.1. Cambridge: Cambridge University Press, 2011. Disponível em: 
http://www.englishprofile.org/images/pdf/theenglishprofilebooklet.pdf. Acesso em: 11 fev. 2018.

GloDEsc. Dicionário Global Escolar Silveira Bueno da Língua Portuguesa. São Paulo: Global, 2016.796p.

HARTMANN, R. R. K.; JAMES, G. Dictionary of Lexicography. London: Routledge, 2001. 176p.

HERBST, T.; KLOTZ, M. Lexikographie. Paderborn: Ferdinand Schöningh, 2003.

Hou. HOUAISS, A. Dicionário Houaiss da Língua Portuguesa.Rio de Janeiro: Objetiva, 2009. $1986 \mathrm{p}$.

KET. CAMBRIDGE ENGLISH LANGUAGE ASSESSMENT. Vocabulary List. Key English Test (KET), Key English Test for Scholars (KETfS). Cambridge: University of Cambridge Local Examinations Syndicate, 2012.

LGwtbDaF Langenscheidt Gro $\beta$ wörterbuch Deutsch als Fremdsprache. Berlin: Langenscheidt: München / Wien, 2015.

LexPäd. JORDAN, Stefan; SCHLÜTER, Marnie (Hrsg.) Lexikon Pädagogik. Hundert Begriffe. Stuttgart: Philipp Reclam, 2010. 320p.

MÖHRING, Jupp; WALLNER, Franziska. Wortschatzlisten auf dem Prüfstand. In: Aussiger Beiträge. Germanistische Schriftreihe aus Forschung und Lehre 7. Ústi nad Labem, 2013, 119-133.

MOURA NEVES, M. H. Guia de Usos do Português: confrontando regras e usos. São Paulo: Editora UNESP, 2003.

OALD. OUP. Oxford Advanced Learner's Dictionary. Oxford: OUP, 2010. 2126 p.

Profile dt. GLABONIAT, M.; MÜLLER, M.; RUSCH, P.; SCHMITZ, H.; WERTENSCHLAG, L. Profile deutsch. Gemeinsamer europäischer Referenzrahmen. Langenscheidt: München, 2002.

Profile dt. GLABONIAT, M.; MÜLlER, M.; RUSCH, P.; SCHMITZ, H.; WERTENSCHLAG, L. Profile deutsch. Gemeinsamer europäischer Referenzrahmen. Langenscheidt: München, 2005. 
QECRL. CONSELHO DA EUROPA. Quadro Europeu Comum de Referência para as línguas: aprendizagem, ensino, avaliação. Portugal: Edições ASA, 2001. Disponível em: $\quad$ http://www.dge.mec.pt/quadro-europeu-comum-de-referencia-para-linguas. Acesso em: 09 fev. 2018.

RICHARDS, J.; SCHMIDT, R.. Longman Dictionary of Language Teaching and Applied Linguistics. Harlow: Longman, 2010.664p.

ROTHENHÖFER, A. New developments in learner's dictionaries II: German. In: GOUWS, R.; HEID, U.; SCHWEICKARD, W.; WIEGAND, H. E. (ed.). Wörterbücher, Dictionaries, Dictionnaires. An international Encyclopedia of Lexicography. Supplementary volume. Berlin: de Gruyter, 2013, p. 414-425.

Sacc. SACCONI, L. A. Grande Dicionário Sacconi da Língua Portuguesa: comentado, crítico e enciclopédico. São Paulo: Nova geração, 2010. 2087 p.

Threshold 1990. VAN ECK, J.A.; TRIM, L.M. Threshold. Cambridge: CUP, 1998.

Vantage. VAN ECK, J.A.; TRIM, LM. Vantage. Cambridge: CUP, 2001.

Waystage 1990. VAN ECK, J.A.; TRIM, L.M. Waystage. Cambridge: CUP, 1991.

WtbPhil. ROGENBOGEN, Armin; MEYER, Uwe (Hrsg.). Wörterbuch der philosophischen Begriffe. Hamburg: Felix Meiner, 2013. 895p.

ZGUSTA, L. A manual of lexicography. Prague: Academy of Sciences, 1971. 